\title{
Correction to: Optical image compression and encryption transmission-based ondeep learning and ghost imaging
}

\author{
Leihong Zhang ${ }^{1} \cdot$ Rui Xiong $^{1}$ (1) $\cdot$ Jian Chen $^{2} \cdot$ Dawei Zhang $^{3}$
}

Published online: 4 February 2020

c) Springer-Verlag GmbH Germany, part of Springer Nature 2020

\section{Correction to: Applied Physics B (2020) 126:18}

https://doi.org/10.1007/s00340-019-7362-1

The article "Optical image compression and encryption transmission-based ondeep learning and ghost imaging", written by "Leihong Zhang, Rui Xiong, Jian Chen, and Dawei Zhang", was originally published electronically on the publisher's internet portal (currently SpringerLink) on 23rd December 2019 with open access. With the author(s)' decision to step back from Open Choice, the copyright of the article changed on 20th January 2020 to (C) Springer-Verlag GmbH Germany, part of Springer Nature 2020 and the article is forthwith distributed under the terms of copyright.

The original article has been updated.

Publisher's Note Springer Nature remains neutral with regard to jurisdictional claims in published maps and institutional affiliations.

The original article can be found online at https://doi.org/10.1007/ s00340-019-7362-1.

\section{Rui Xiong}

xiongrui2017usst@sina.com

1 College of Communication and Art Design, University of Shanghai for Science and Technology, Shanghai 200093, China

2 Anhui Province Key Laboratory of Non-Destructive Evaluation, Hefei ZC Optoelectronic Technologies Ltd, Anhui 230000, China

3 School of Optical-Electrical and Computer Engineering, University of Shanghai for Science and Technology,

Shanghai 200093, China 